\title{
PERFECTIBILIDADE, LIBERDADE E EDUCAÇÃO EM ROUSSEAU
}

Paulo César Nodari ${ }^{1}$

\begin{abstract}
Resumo:
O objetivo deste ensaio é apresentar três conceitos-chave do pensamento rousseauniano: perfectibilidade, liberdade e educação. Trata-se de uma breve elucidação desses três conceitos, a fim de entender melhor a notável passagem do estado de natureza ao estado civil em Rousseau.
\end{abstract}

Palavras-chave: Perfectibilidade. Liberdade. Educação. Estado de Natureza. Estado Civil.

\section{PERFECTIBILITY, FREEDOM AND EDUCATION IN ROUSSEAU}

\begin{abstract}
:
The aim of this essay is to present three key concepts of Rousseau's thinking: perfectibility, freedom and education. It is a brief elucidation of these three concepts in order to better understand the remarkable passage from the state of nature to the civil state in Rousseau.
\end{abstract}

Keywords: Perfectibility. Freedom. Education. State of Nature. Civil State.

O objetivo deste texto é apresentar três conceitos importantes da obra de JeanJacques Rousseau, a saber: perfectibilidade, liberdade e educação. Trata-se de uma reflexão que busca traçar alguns aspectos importantes para a compreensão do pensamento do denominado sempre polêmico e controverso autor genebrino do século das luzes. Este ensaio não tem o intento de analisar, aprofundar e ou inovar na leitura e compreensão das principais obras de Rousseau, aqui, referenciadas: Primeiro Discurso, Segundo Discurso, Emílio, Contrato Social, mas, por sua vez, articular algumas ideias imprescindíveis para a compreensão do pensamento rousseauniano na medida em que, por um lado, a história e a cultura influenciam na formação do ser humano e do status civil, porém, ao mesmo tempo, por outro, na medida em o ser humano, enquanto livre e aberto ao processo de perfectibilidade, pode vir a questionar, a rejeitar e a aperfeiçoar a vida pessoal, a cultura e o estado civil.

Para Rousseau ${ }^{2}$, filósofo genebrino, a natureza concede ou "condecora" os homens com uma faculdade - a perfectibilidade - que constitui o meio através do qual os

1 Professor no PPGFIL (Programa de Pós-Graduação em Filosofia: Mestrado e Doutorado) e no PPGDIR (Programa de Pós-Graduação em Direito: Mestrado e Doutorado) da Universidade de Caxias do Sul. E-mail: paulocesarnodari@hotmail.com. 
homens se afastam da natureza mesma. Esta faculdade tipicamente humana, isto é, a faculdade de aprender a melhorar-se e ao mesmo tempo de afastar-se do estado autárquico original, torna-se, no final das contas, por um lado, um dos fatores decisivos para o processo da socialização do ser humano, e, por outro, uma das causas, senão a principal causa de todo o mal humano. Logo, o conceito perfectibilidade é ingrediente principal para a compreensão do pensamento de Rousseau. Frisa-se que tal conceito não tem o espectro tecnocientífico da concepção contemporânea acerca do aperfeiçoamento, o qual está sob a égide e domínio da tecnologia e da ciência. Em todo caso, a noção de perfectibilidade no âmbito da antropologia e da ética não era exclusividade de Rousseau no século XVIII (DALBOSCO, 2016, p. 113). Assim, o que se apresentava como um modelo teleológico leva a um resultado antiteleológico, pois a natureza, através da sua "dádiva", não consegue mais do que tornar os homens mais infelizes. Assevera, ironicamente, Rousseau: “É um espetáculo grandioso e belo ver o homem sair, por seu próprio esforço, a bem dizer do nada; dissipar, por meio das luzes de sua razão, as trevas nas quais o envolveu a natureza [...].” (ROUSSEAU, Primeiro Discurso, p. 343). A partir desse momento, a história humana volta-se e torna-se a história do desenvolvimento da racionalidade e da liberdade humanas, pois ambas são expressões da mesma realidade, a saber, da autonomia humana. Afirma Rousseau:

Eis, pois, todas as nossas faculdades desenvolvidas, a memória e a imaginação em ação, o amor-próprio interessado, a razão em atividade, alcançando o espírito quase

2 Jean-Jacques Rousseau (1712-1778) foi um filósofo suíço, nascido em Genebra, escritor, teórico político e um compositor musical. É considerado uma das figuras marcantes do Iluminismo francês e precursor do romantismo. Ele era filho do relojoeiro calvinista Isaak Rousseau, e, segundo dados, ele não conheceu sua mãe, pois faleceu no parto de Jean-Jacques. Seu pai morreu, quando ele tinha 10 anos. Rousseau teve uma juventude bem agitada, morou em lugares diferentes e sua juventude, além de agitada, pode-se dizer, foi de muitas buscas, e, também, sofrimento. Ele gostava muito de passear pela natureza. Rousseau não tinha condições financeiras muito favoráveis. Morou em Paris. Tornou-se famoso, em Paris, sobretudo, no campo da música. Escreveu uma ópera que lhe deu sucesso, intitulada: $O$ Adivinho da Vila. Torna-se famoso ao escrever para um concurso em Dijon em 1750, ganhando o prêmio com o Discurso sobre as ciências e as artes. Ele tem cinco filhos com uma amante em Paris e coloca-os num orfanato. Por ironia do destino, escreve, mais tarde, o Emílio ou Da Educação, versando sobre como educar as crianças. Escreve ainda, entre outras obras, A Nova Heloísa, Confissões. Politicamente, expõe suas ideias no Contrato Social. Procura um Estado social legítimo, próximo da vontade geral e distante da corrupção. A soberania do poder, para ele, deve estar nas mãos do povo, através do corpo político dos cidadãos. Segundo suas ideias, a população tem que tomar cuidado ao transformar seus direitos naturais em direitos civis, afinal o homem nasce bom e a sociedade o corrompe. Depois de toda uma produção intelectual, suas fugas às perseguições e uma vida de aventuras, Rousseau passa a levar uma vida retirada e solitária. Por opção, ele foge dos outros homens. Nesta época, ele dedica-se à natureza, que sempre foi uma de suas paixões. Seu grande interesse por botânica leva-o a recolher espécies e montar um herbário. Seus relatos desta época estão no livro Devaneios de Caminhante Solitário. Rousseau termina por falecer aos 66 anos, onde estava hospedado, no Castelo de Ermenonville. Entretanto, até os dias de hoje, ele ainda é um provocador, que leva muitos a acreditarem na bondade natural do ser humano e de como a sociedade acaba destruindo essa bondade. E, por muitos, não é esquecido por sua forte crítica à propriedade privada, como causa da miséria entre as pessoas. Rousseau foi um iluminista à parte, talvez pelas suas próprias experiências desde a infância. 
que o termo da perfectibilidade de que é suscetível. Aí estão todas as qualidades naturais postas em ação, estabelecidos a posição e o destino de cada homem, não somente quanto à quantidade dos bens e o poder de servir ou de ofender, mas também quanto ao espírito, à beleza, à força e à habilidade, quanto aos méritos e aos talentos e, sendo tais qualidades as únicas que poderiam merecer consideração, precisou-se desde logo possui-las. Para proveito próprio, foi preciso mostrar-se diferente do que na realidade se era. Ser e parecer tornaram-se duas coisas totalmente diferentes. Dessa distinção resultaram o fausto majestoso, a astúcia enganadora e todos os vícios que lhes formam cortejo. Por outro lado, o homem, de livre e independente que antes era, devido a uma multidão de novas necessidades passou a estar sujeito, por assim dizer, a toda a natureza e, sobretudo, a seus semelhantes dos quais num certo sentido se torna escravo, mesmo quando se torna senhor: rico, tem necessidade de seus serviços; pobre, precisa de seu socorro, e a mediocridade não o coloca em situação de viver sem eles. É preciso, pois, que incessantemente procure interessá-los pelo seu destino e fazer com que achem, real ou aparentemente, residir o lucro deles em trabalharem para o seu próprio. Isso faz com que seja falso e artificioso para com uns, e, para com outros, imperativo e duro, e o coloca na contingência de iludir a todos aqueles de que necessita, quando não pode fazer-se temer por eles ou não considera de seu interesse ser-lhes útil. Por fim, a ambição devoradora, o ardor de elevar sua fortuna relativa, menos por verdadeira necessidade do que para colocar-se acima dos outros, inspira a todos os homens uma negra tendência a prejudicarem-se mutuamente, uma inveja secreta tanto mais perigosa quanto, para dar seu golpe com maior segurança, frequentemente usa a máscara da bondade; em uma palavra, há, de um lado, concorrência e rivalidade, de outro, oposição de interesses e, de ambos, o desejo oculto de alcaçar lucros a expensas de outrem. Todos esses ales constituem o primeiro efeito da propriedade e o cortejo inserparável da desigualdade nascente." (ROUSSEAU, Segundo Discurso, p. 273).

A pergunta que vem com muita facilidade e frequência à tona é se a perfetibilidade constituir-se-ia em uma contradição, ou então, na expressão kantiana, em uma espécie de "antagonismo", justamente, porque, para Rousseau, a possibilidade contínua de aperfeiçoamento, possível graças à sua liberdade, é talvez uma das principais causas da origem da desigualdade entre os seres humanos. "Juntamente com a liberdade, a perfectibilidade foi um fator decisivo para que o ser humano se tornasse capaz de ir além daquilo que sua carga instintiva lhe determinava." (DALBOSOCO, 2016, p. 118). A qualidade específica do ser humano é a possibilidade contínua de aperfeiçoar-se (ROUSSEAU, Segundo Discurso, p. 249), provavelmente, a causa principal da desigualdade entre os homens (ROUSSEAU, Segundo Discurso, p. 249), e, também, uma das causas das ingerências ao conhecimento do próprio ser humano. Assevera, nessa perspectiva, Rousseau: “O que há de mais cruel ainda é que, todos os progressos da espécie humana distanciando-a incessantemente de seu estado primitivo, quanto mais acumulamos novos conhecimentos, tanto mais afastamos os meios de adquirir o mais importante de todos: é que, num certo sentido, à força de estudar o homem, tornamo-nos incapazes de conhecê-lo." (ROUSSEAU, Segundo Discurso, p. 233: grifos do autor). Diferentemente dos animais, o ser humano vai definir-se, ao mesmo tempo, por sua liberdade, por sua capacidade de se libertar do programa

\begin{tabular}{|l|l|l|l|l|}
\hline Govista Qialectus & Ano 8 & n. 15 & Agosto-Dezembro 2019 & p. 253 - 267 \\
\hline
\end{tabular}


do instinto natural (FERRY, 2007, p. 130). Toma-se, a seguir, uma passagem do Emílio, a fim de auxiliar na resposta ao entendimento do conceito perfectibilidade. Sublinha Rousseau:

\begin{abstract}
Foi assim que a natureza, que tudo faz do melhor modo, inicialmente o instituiu. Ela lhe dá de imediato apenas os desejos necessários à sua conservação e as faculdades suficientes para satisfazê-los. Ela colocou todas as outras como que de reserva no fundo de sua alma, para que se desenvolvessem quando necessário. Só nesse estado primitivo o equilíbrio entre o poder e o desejo é reencontrado e o homem não é infeliz. Assim que suas faculdades virtuais se põem em ação, a imaginação, a mais ativa de todas, desperta e as ultrapassa. É a imaginação que amplia para nós a medida dos possíveis, tanto para o bem quanto para o mal e, por conseguinte, provoca e nutre os desejos com a esperança de satisfazê-los. No entanto, o objeto que antes parecia estar à mão foge tão depressa que não podemos alcançá-lo; quando acreditamos que vamos pegá-lo, ele se transforma e aparece longe à nossa frente. Não vendo mais o espaço já percorrido, consideramo-lo como nada, ao passo que o que resta a percorrer cresce e se amplia sem cessar. Assim, esgotamo-nos sem chegar ao final e, quanto mais vencemos o prazer, mais a felicidade se afasta de nós. Pelo contrário, quanto mais o homem tiver permanecido próximo à sua condição natural, mais a diferença entre as suas faculdades e os seus desejos será pequena e, consequentemente, menos distante estará de ser feliz. Nunca ele é menos miserável do que quando parece carente de tudo, pois a miséria não consiste na privação das coisas, mas na necessidade que sentimos delas. (ROUSSEAU, Emílio, p. 70).
\end{abstract}

Na época de Rousseau, havia, sobretudo, duas características diferenciadoras

do ser humano com relação aos animais. Para distinguir o ser humano dos animais, de um lado, tinha-se a inteligência, e, de outro, tinha-se a sensibilidade, a afetividade e a sociabilidade. Para Aristóteles, por exemplo, o ser humano é um animal racional e político, ou seja, capaz de raciocínio e capaz de sociabilidade. Para Descartes, ainda que controverso, o ser humano é uma espécie de "máquina engenhosa" capaz e possuidor de inteligência e dotado de capacidade afetividade, linguagem e sociabilidade. Porém, para Rousseau, a característica própria do ser humano e que o diferenciará dos animais será a liberdade. Constitui-se na mais nobre das faculdades do ser humano, e, em se degradando da mesma, estaria o ser humano degradando sua própria natureza (ROUSSEAU, Segundo Discurso, p. 280). A liberdade é o aspecto principal e originário do distanciamento do ser humano com relação aos animais. "Renunciar à liberdade é renunciar à qualidade de homem, aos direitos da humanidade, e até aos próprios deveres. Não há recompensa possível para quem a tudo renuncia.” (ROUSSEAU, Contrato Social, I, 4, p. 33). Logo, partindo do princípio moral de que o ser humano é naturalmente bom, ou seja, a natureza o fez feliz e bom, Rousseau mostra, no Segundo Discurso que a característica principal que diferencia o ser humano do animal é a liberdade. O ser humano é um ser livre e tem condições e capacidade para querer e não 
querer, desejar e temer, sendo, por conseguinte, a liberdade um dom que lhe vem da natureza (ROUSSEAU, Segundo Discurso, p. 281).

O curioso em Rousseau é que tal característica do ser humano é de uma certa paradoxalidade, ou seja, ainda que a possibilidade contínua de aperfeiçoamento seja provavelmente a principal causa da desigualdade, ela, ao mesmo tempo, constitui-se, além da liberdade, na outra qualidade específica do ser humano (ROUSSEAU, Segundo Discurso, p. 161). Para entender melhor, faz-se urgente rememorar que, para Rousseau, há dois tipos bem distintos de desigualdade, a saber, a desigualdade natural ou física, estabelecida pela natureza que consiste na diferença das idades, da saúde, das forças do corpo e das qualidades do espírito e alma, e a desigualdade moral ou política, dependente de uma espécie de convenção e que é estabelecida ou, pelo menos, autorizada pelo consentimento dos seres humano, consistindo em vários privilégios de que gozam alguns em detrimento de outros, como o serem mais ricos, mais homenageados, ou ainda, por fazerem-se obedecer. Trata-se de uma passagem longa, mas muito interessante de Rousseau do Segundo Discurso. Eis uma passagem paradigmática.

Em cada animal vejo somente uma máquina engenhosa a que a natureza conferiu sentidos para recompor-se por si mesma e para defender-se, até certo ponto, de tudo quando tende a destrua-la ou estragá-la. Percebo as mesmas coisas na máquina humana, com a diferença de tudo fazer sozinha a natureza nas operações do animal, enquanto o homem executa as suas como agente livre. Um escolhe ou rejeita por instinto, e o outro, por um ato de liberdade, razão por que o animal não pode desviar-se da regra que lhe é prescrita, mesmo quando lhe fora vantajoso fazê-lo, e o homem em seu prejuízo, frequentemente se afasta dela. Assim, um pombo morreria de fome perto de um prato cheio das melhores carnes e um gato sobre um monte de frutas ou de sementes, embora tanto um quanto outro pudessem alimentar-se muito bem com o alimente que desdenham, se fosse atilado para tentá-lo; assim, os homens dissolutos se entregam a excessos que lhe causam febre e morte, porque o espírito deprava os sentido e a vontade ainda fala quando a natureza se cala.

Todo animal tem ideias, posto que tem sentidos; chega mesmo a combinar suas ideias até certo ponto e o homem, a esse respeito, só se diferencia da besta pela intensidade. Alguns filósofos chegaram mesmo a afirmar que existe maior diferença entre um homem e outro do que entre certo homem e certa besta. Não é, pois, tanto o entendimento quanto a qualidade de agente livre possuída pelo homem que constitui, entre os animais, a distinção específica daquele. A natureza manda em todos os animais, e a besta obedece. $\mathrm{O}$ homem sofre a mesma influência, mas considera-se livre para concordar ou resistir, e é, sobretudo na consciência dessa liberdade que se mostra a espiritualidade de sua alma, pois a física de certo modo explica o mecanismo dos sentidos e a formação das ideias, mas no poder de querer, ou antes, de escolher e no sentimento desse poder só se encontram atos puramente espirituais que de modo algum serão explicados pelas leis da mecânica.

Mas, ainda quando as dificuldades que cercam todas essas questões deixassem por um instante de causar discussão sobre diferença entre o homem e o animal, haveria outra qualidade muito específica que os distinguiria e a respeito da qual não pode haver contestação - é a faculdade de aperfeiçoar-se, faculdade que, com o auxílio das circunstâncias, desenvolve sucessivamente todas as outras e se encontra, entre nós, tanto na espécie quanto no indivíduo; o animal, pelo contrário, ao fim de alguns meses, é o que será por toda a vida, e sua espécie, no fim de milhares de anos, o que

\begin{tabular}{|l|l|l|l|l|}
\hline Govista Qialectus & Ano 8 & n. 15 & Agosto - Dezembro 2019 & p. 253 - 267 \\
\hline
\end{tabular}


era no primeiro ano desses milhares. Por que só o homem é suscetível de tornar-se imbecil? Não será porque volta, assim, ao seu estado primitivo e - enquanto a besta, que nada adquiriu e também nada tem de bom a perder, fica sempre com seu instinto - o homem, tornando a perder, pela velhice ou por outros acidentes, tudo o que sua perfectibilidade lhe fizera adquirir, volta a cair, desse modo, mais baixo do que a própria besta? Seria triste, para nós, vermo-nos forçados a convir que seja essa faculdade, distintiva e quase ilimitada, a fonte de todos os males do homem; que seja ela que, com o tempo, o tira dessa condição original na qual passaria dias tranquilos e inocentes; que seja ela que, fazendo com que através dos séculos desabrochem suas luzes e erros, seus vícios e virtudes, o torna com o tempo o tirano de si mesmo e da natureza. Seria horrível ter de louvar como um ser benfeitor o primeiro a sugerir aos habitantes das margens do Orinoco o uso dessas tabuazinhas que aplicam nas têmporas de seus filhos e que, pelo menos, lhes asseguram uma parte de sua imbecilidade e de sua felicidade original. (ROUSSEAU, Segundo Discurso, pp. 248249: grifo do autor).

A liberdade é a condição de possibilidade para pensar o ser humano como tal. Portanto, o ser humano ou é livre ou deixa de sê-lo. A liberdade lhe pertence e renunciar a ela é renunciar à própria qualidade de ser humano. Rousseau busca, por conseguinte, compreender a liberdade em seu ato fundador. Este acontece no momento da convenção, no qual o instinto moral cessa de ser instinto para tornar-se vontade. Dá-se, por assim dizer, na passagem do estado natural ao estado civil. Todavia, já, no Segundo Discurso, Rousseau tem a compreensão de que o ser humano é um ser livre, sendo a liberdade, por sua vez, a característica principal que diferencia o ser humano dos animais. De acordo com Rousseau, no estado natural o ser humano é livre e desfruta da liberdade natural. Todos os seres humanos nascem livres e iguais. Ninguém tem autoridade sobre outrem. Mas a liberdade no estado natural apresenta riscos, os quais precisam ser superados, sobretudo, porque o ser humano no estado natural busca sua conservação. Basta-se a si mesmo. É autossuficiente. Não consegue viver em sociedade. Por isso, por meio do contrato social, pacto convencional de associação, o ser humano deixa o estado natural e entra no estado civil, dando-se a aquisição da liberdade moral, constituindo-se numa mudança notável para o ser humano. Afirma Rousseau: “[...] sendo quase nula a desigualdade no estado de natureza, deve sua força e seu desenvolvimento a nossas faculdades e aos progressos do espírito humano, tornando-se, afinal, estável e legítima graças ao estabelecimento da propriedade e das leis." (ROUSSEAU, Segundo Discurso, p. 288). A passagem do estado de natureza ao estado civil marca uma mudança muito importante e determinante para o prosseguimento da existência humano e para o convívio entre os seres humanos. Ainda que possa trazer-lhe preocupações e dificuldades, a mudança traz-lhe também benefícios, especialmente, a segurança e a proteção sob a égide do direito. Afirma Rousseau:

\begin{tabular}{|l|l|l|l|l|}
\hline Govista Qialectus & Ano 8 & n. 15 & Agosto - Dezembro 2019 & p. 253 - 267 \\
\hline
\end{tabular}




\begin{abstract}
A passagem do estado de natureza para o estado civil determina no homem uma mudança muito notável, substituindo na sua conduta o instinto pela justiça e dando às suas ações a moralidade que antes lhes faltava. É só então que, tomando a voz do dever o lugar do impulso físico, e o direito o lugar do apetite, o homem, até aí levando em consideração apenas sua pessoa, vê-se forçado a agir baseando-se em outros princípios e a consultar a razão antes de ouvir suas inclinações. Embora nesse estado se prive de muitas vantagens que frui da natureza, ganha outras de igual monta: suas faculdades se exercem e se desenvolvem, suas ideias se alargam, seus sentimentos se enobrecem, toda a sua alma se eleva a tal ponto, que, se os abusos dessa nova condição não o degradassem frequentemente a uma condição inferior àquela donde saiu, deveria sem cessar bendizer o instante feliz que dela o arrancou para sempre e fez, de uma animal estúpido e limitado, um ser inteligente e um homem. (ROUSSEAU, Contrato Social, I, VIII, p. 42).
\end{abstract}

A liberdade é o veio que move todo projeto político de Rousseau. Porém, o uso incorreto da liberdade pode fazer do próprio ser humano uma presa do mal. Ou seja, o resultado de um mau uso da liberdade humana deve-se não apenas à dimensão pessoal, ou seja, apenas ao indivíduo, mas, sobretudo, também, à civilização, isto é, a uma situação exterior ao indivíduo, à sociedade, pois a responsabilidade pelo surgimento do mal se deve à civilização, ou melhor, à sociedade. Entretanto, para Rousseau, o ser humano, enquanto presa do mal, não deverá, como no cristianismo, ser remido ou perdoado. Precisará, unicamente, com auxílio da consciência, da natureza e da razão, restaurar a ordem alcançando-a na sociedade civil, aplicando uma educação preventiva e progressiva. Porque o melhor modo de corrigir a maldade humana é a educação, cuja finalidade é o exercício constante da liberdade no transcurso da vida da infância até a idade adulta na sociedade civil, tornando-os cidadãos. É um processo contínuo e aberto tanto em nível pessoal quanto em nível societário. Mesmo sabendo que o pacto fundamental, isto é, o contrato social, marque e legitime artificialmente, ou seja, convencionalmente, a igualdade entre os humanos, Rousseau tem consciência das dificuldades múltiplas da convivência social e da manutenção da igualdade entre os mesmos. Dá-se a passagem notável. Cabe a preservação, ou seja, a garantia e a busca incessante pela igualdade e pela manutenção da liberdade dos e entre os cidadãos, o que se constitui em uma tarefa absolutamente árdua, intensa e inacabada. "Porque o homem é perfectível, não cessou de acrescentar suas invenções aos dons da natureza." (STAROBINSKI, 19991, p. 24). É uma espécie de prática humilde e silenciosa, porém contínua e permanente, porque o ser humano é, por sua própria natureza, aberto infinitamente à perfectibilidade e tem o poder de se libertar do mal (STRAUSS, 1986, p. 234). E, com a finalidade de asseverar sua capacidade e possibilidade infinita de progredir, acentua Rousseau a respeito do passo notável da passagem do estado de natureza ao estado civil: "[...] o pacto fundamental, em lugar de destruir a igualdade natural, pelo contrário substitui por uma igualdade moral e legítima aquilo que a

\begin{tabular}{|l|l|l|l|l|}
\hline Govista Qialectus & Ano 8 & n. 15 & Agosto - Dezembro 2019 & p. 253 - 267 \\
\hline
\end{tabular}


natureza poderia trazer de desigualdade física entre os homens, que, podendo ser desiguais na força ou no gênio, todos se tornam iguais por convenção e direito.” (ROUSSEAU, Contrato Social, I, IX, p. 45).

Trata-se de um dos meios e ingredientes importantes para a convivência sadia entre os humanos e a para a preservação da liberdade e da igualdade entre os mesmos, é missão da educação. No Emílio, é mostrada a marcha da natureza, ou seja, o crescimento natural da criança até a fase adulta. A educação precisará ser uma espécie de "desnaturalização natural", isto é, elevar a criança acima da natureza, porém sem opor-se a ela. Há uma estreita relação no pensamento de Rousseau entre a educação e a política. De acordo com essa interpretação, o único modo de desenvolver a liberdade é a aceitação do limite como algo objetivo sem transladá-lo ao campo da própria subjetividade. O modo de ir corrigindo a maldade humana é uma educação cuja finalidade seja o exercício da liberdade no transcurso da vida. É possibilidade de regeneração do homem, uma vez que, segundo Rousseau, o homem foi levado à corrupção pelo advento da civilização. No início do Emílio, Rousseau diz que "tudo é bom saindo das mãos do Autor das coisas e tudo degenera nas mãos dos homens". Todavia, a corrupção não atingiu a natureza do ser humano, e, por isso, não se faz necessária uma intervenção externa. O ser humano precisa encontrar, em si mesmo, a capacidade de sua redenção ética e política, reconquistando, segundo uma nova perspectiva histórica, aquela fase originária natural de bondade não contaminada, não necessitando, entretanto, voltar ao estado natural primitivo, pois, para Rousseau, a história não pode ser repetida, uma vez que o progresso é irreversível. Rousseau sabe muito bem que o hipotético tempo da inocência e da igualdade não pode ser alcançado com uma volta ao estado de natureza, porém acredita em uma recuperação pessoal (Emílio) e coletiva (Do Contrato Social) das condições originárias da bondade "O que o homem perde pelo contrato social, é a liberdade natural e o direito ilimitado a tudo quanto aventura e pode esperar. O que ele ganha é a liberdade civil e a propriedade de tudo que possui" (ROUSSEAU, Contrato Social, I, 8, p. 42).

A educação tem como objetivo central formar um ser humano livre, capaz de se defender contra todos os constrangimentos, e, para formá-lo livre há apenas um meio de tratá-lo como um ser livre, respeitar a liberdade de todos, no caso da criança, tratá-la como um ser livre, respeitando sua liberdade como criança. A criança não é escrava dos pais e muito menos dos chamados preceptores da época de Rousseau. Aqui, talvez, esteja o que se pode chamar da revolução rousseauniana. A criança passa a ser vista como ser humano digno de 
respeito. Ela passa a ter condição de pessoa. No Emílio, a atenção de Rousseau não estava voltada para a formação do burguês e nem para a educação do cidadão, e sim para a educação do ser humano, pondo-se em evidência as necessidades essenciais da criança. "Em vez de educar Emílio para um determinado papel social, como é o procedimento comum em sociedade, propõe educá-lo para ser homem, isto é, segundo a natureza, para melhor viver em sociedade, guardando as qualidades naturais.” (PISSARA, 2005, p. 57). Em Rousseau, é importante compreender o seguinte impasse: a sociabilidade, segundo Rousseau, corrompeu o ser humano, tornando-o vicioso e infeliz, porém, por outro lado, não significa afirmar que ele não deveria tornar-se um ser social ou então que o ser humano devesse voltar necessariamente ao estado natural. É, também, urgente dar-se por conta de que o ser humano é um ser que caminha para a perfeição, ou seja, ele não está pronto, antes e muito mais, identifica-se com a capacidade de desenvolver, indefinidamente, seu caminho e rumar para a perfeição e realização. "Em síntese, a noção de perfectibilité permite a Rousseau compreender a história como um processo aberto no qual as disputas estão permanentemente em jogo, sem que a ascensão ou o declínio possam ser decididos previamente.” (DALBOSCO, 2016, p. 122). Acentua, por sua vez, Pissara:

\begin{abstract}
Para haver uma sociedade justa e equilibrada é preciso liberdade; para que esta seja possível são necessários cidadãos virtuosos, que só existem sob o império da virtude. Refletir sobre as condições morais da preparação do cidadão para sua entrada na sociedade é complementar a reflexão política dando-lhe sentido, isto é, trata-se de refletir sobre a necessidade de uma reforma política anunciada pelos dois Discursos. (PISSARA, 2005, p. 56).
\end{abstract}

Numa palavra, significa afirmar, por um lado, a preocupação de Rousseau acerca dos problemas teóricos da educação à luz de uma reflexão filosófica, e, por outro lado, a íntima ligação entre as quatro obras aqui referenciadas em um espectro amplo, na medida em que Rousseau, no Primeiro Tratado, ele critica o modo como as ciências e as artes acabam por enaltecer o discurso da aparência e do status quo de sua época, no Segundo Discurso, apresenta as principais características diferenciadoras do ser humano e dos animais e a origem das desigualdades entres os seres humanos, no Emílio ou da educação, argumenta e desenvolver a perspectiva da educação do indivíduo como tal, tomando em consideração os diferentes mestres da educação e os distintos estágios da educação, e, no Contrato Social, analisa e articula os principais passos a serem entendidos e realizados para uma educação e convivência civil facilitadoras do desenvolvimento e compreensão da educação e da história como processo aberto, tanto para a superação da maldade, da corrupção, como também, para

\begin{tabular}{|c|c|c|c|}
\hline Q Ponista Dialectus & \begin{tabular}{l|l} 
Ano 8 & n. 15
\end{tabular} & Agosto - Dezembro 2019 & p. $253-267$ \\
\hline
\end{tabular}


um contínuo questionamento da cultura enquanto processo de permanente aprendizagem e construção do denominado estado civil, no qual os seres humanos possam sentir-se seguros, livres e felizes. Sabe-se, porém, que, para Rousseau, o caminho é muito exigente. Sublinha Rousseau: "O homem de bem é um atleta que se compraz em combater nu; despreza todos esses ornamentos vãos, que dificultam o emprego de suas forças e cuja maior parte só foi inventada para esconder uma deformidade qualquer." (ROUSSEAU, Primeiro Discurso, p. 344). Não é mais possível aceitar a tese da aparência de "[...] uma uniformidade desprezível e enganosa, e parece que todos os espíritos se fundiram num mesmo molde [...]" (ROUSSEAU, Primeiro Discurso, p. 344), tornando-a um padrão a ser observado e seguido, ou seja, a conditio sine qua non, acabando por desvirtuar-se em uma quase que virtude. Acentua, uma vez mais, Rousseau: "Não mais amizades sinceras e estima real; não mais confiança cimentada. As suspeitas, os receios, os medos, a frieza, a reserva, o ódio, a traição esconderse-ão sob esse véu uniforme e pérfido da polidez, sob essa urbanidade tão exaltada que devemos às luzes de nosso século." (ROUSSEAU, Primeiro Discurso, p. 344). Enfim, é urgente recordar que, para Rousseau, é a fraqueza que torna o ser humano sociável, porque, por natureza, o ser humano é solitário e não dado a associar-se, naturalmente. Segundo Strauss, como em Hobbes, em Rousseau o ser humano não é naturalmente sociável. Mas, porque o orgulho ou o amor-próprio pressupõe a sociedade, Rousseau, diferentemente de Hobbes, acentua a tese de que o ser humano, no estado de natureza, está despido de todo vício, e revestido pelo amor de si, isto é, de anseio pela sua conservação (STRAUSS, 1986, p. 233). Nessa perspectiva, muito provavelmente: “A fraqueza do homem torna-o sociável e nossas misérias comuns levam nossos corações à humanidade; nada lhe deveríamos se não fôssemos homens.” (ROUSSEAU, Emílio, p. 286). Logo, segundo Rousseau:

É preciso estudar a sociedade pelos homens, e os homens pela sociedade; quem quiser tratar separadamente a política e a moral nada entenderá de nenhuma das duas. Abordando primeiramente as relações primitivas, vemos como os homens devem ser afetados por elas e que paixões devem nascer delas; vemos que é em reciprocidade ao progresso das paixões que essas relações se multiplicam e se estreitam. É menos a força dos braços do que a moderação dos corações que torna os homens independentes e livres. Quem deseja pouca coisa depende de pouca gente, mas, sempre confundindo nossos vãos desejos com nossas necessidades físicas, aqueles que fizeram destas últimas os fundamentos da sociedade humana sempre tomaram os efeitos pelas causas e apenas se desorientaram em todos os seus raciocínios. (ROUSSEAU, Emílio, p. 309).

Nessa seara, urge recordar, a fim de alcançar uma melhor compreensão do pensamento político-pedagógico de Rousseau, que o amor de si, diferentemente do amorpróprio, não deve ser confundido com orgulho e egoísmo. O amor-próprio significa

\begin{tabular}{|l|l|l|l|l|}
\hline Govista Dialectus & Ano 8 & n. 15 & Agosto - Dezembro 2019 & p. 253 - 267 \\
\hline
\end{tabular}


sentimento de vaidade, de orgulho e de soberba. Por sua vez, do amor de si provém o sentimento de cuidado da própria conservação. "A fonte de nossas paixões, a origem e o princípio de todas as outras, a única que nasce com o homem e nunca o abandona enquanto ele vive é o amor de si; paixão primitiva, inata, anterior a todas as outras e que todas as outras não passam, em certo sentido, de modificações." (ROUSSEAU, Emílio, p. 273). O amor de si não é ruim. "O amor de si é sempre bom e sempre conforme à ordem.” (ROUSSEAU, Emílio, p. 274). É sempre bom, porque cada um se encarrega de sua conservação e preservação. É preciso que o ser humano se ame a si mais do que qualquer outra coisa para que se conserve. “A oposição da noção de 'amor de si', inteiramente positiva, altruísta, nós encontraremos novamente com a do 'amor-próprio', totalmente negativa, egoísta. É a diferença entre a autopreservação e o egoísmo.” (DA SILVA, 2006, p. 107). Afirma Rousseau.

\begin{abstract}
O amor de si, que só a nós mesmos considera, fica contente quando nossas verdadeiras necessidades são satisfeitas, mas o amor-próprio, que se compara, nunca está contente e nem poderia estar, pois esse sentimento, preferindo-nos aos outros, também exige que os outros prefiram-nos a eles, o que é impossível. Eis como as paixões doces e afetuosas nascem do amor de si, e como as paixões odientas e irascíveis nascem do amor-próprio. Assim, o que torna o homem essencialmente bom é ter poucas necessidades e pouco se comparar com os outros; o que o torna essencialmente mau é ter muitas necessidades e dar muita atenção à opinião. A partir desse princípio, é fácil ver como podemos dirigir para o bem ou para o mal todas as paixões das crianças e dos homens. É verdade que, não podendo viver sempre sozinhos, dificilmente serão sempre boas; essa dificuldade até mesmo aumentará necessariamente com suas relações, e é nisso sobretudo que os perigos da sociedade nos tornam a arte e os trabalhos mais indispensáveis para prevenir no coração humano a depravação que nasce de suas novas necessidades. (ROUSSEAU, Emílio, p. 275).
\end{abstract}

Trata-se, portanto, do denominado segundo nascimento, ou então, a segunda natureza denominada de cultura. Desenvolve-se como que uma segunda natureza. Não se trata de um nascimento biológico, por assim dizer, mas de um nascimento espiritual para a existência, agora, não mais isolado, mas em sociedade, ainda que, segundo Rousseau, seja a fraqueza que torne o ser humano sociável. Numa palavra, é a insuficiência que leva o ser humano a unir-se aos outros em sociedade (ROUSSEAU, Emílio, p. 286). Neste segundo nascimento, pode-se afirmar que a educação passa a ser positiva e o indivíduo precisará ser capaz por si próprio de fazer suas escolhas, pois ele foi preparado para esse momento. Pressupõe-se, portanto, que ele tenha adquirido autonomia para as escolhas. Ele foi educado para aprender da vida e para que nada do que fosse humano lhe fosse alheio e aprendesse, por conseguinte, a viver, em sociedade, para si, com os outros e para os outros (BOTO, 2005, p. 382), e isso, segundo Rousseau, no ser humano, provém de um sentimento original muito 
forte e muito positivo, a saber, o amor de si, ou seja, do desejo de conservação. "Nossas paixões são o principal instrumento de nossa conservação; portanto, é uma tentativa tão vã quanto ridícula querer destruí-las; é governar a natureza, é reformar a obra de Deus." (ROUSSEAU, Emílio, p. 273). Ou ainda, nesse sentido, segundo uma nota de rodapé de página do Segundo Discurso: “O amor de si mesmo é um sentimento natural que leva todo animal a velar pela própria conservação e que, no homem dirigido pela razão e modificado pela piedade, produz a humanidade e a virtude." (ROUSSEAU, Segundo Discurso, p. 312). Por conseguinte, de acordo com Rousseau, é preciso guiar a sensibilidade, a fim de favorecêla na direção das paixões próprias da sociabilidade, da amizade, piedade, amor à humanidade, o amor a Deus, retardando, por conseguinte, a atenção às paixões violentas. O indivíduo precisa ser conduzido a fazer poucas comparações com os outros, ou seja, a não ser instigado a comparar-se com os outros e a não criar necessidades supérfluas. Aos poucos, o indivíduo vai sendo educado a perceber sua relação com os outros, desenvolvendo-se, assim, o ser moral. Essa necessidade social que se manifesta leva-o a estudar a sociedade, a igualdade e a justiça. Essa etapa formativa é sumamente importante, sobretudo, porque, quando levadas ao exagero e mal guiadas, as paixões correm sempre o risco de serem prejudiciais. "Aos poucos, dos sentimentos de amor e ódio, formar-se-ão suas primeiras noções de bem e mal e depois as ideias de justiça e bondade. Quando começa a se perceber mais entre os outros e se comparar com eles, esse jovem pretende-se melhor que todos: nesse momento desperta o amor-próprio e as paixões dele decorrentes.” (PISSARA, 2005, p. 63).

O sentimento do amor de si é de suma relevância, pois o amor de si no relacionamento com o outro se transforma em piedade na medida em que o Emílio não fica centrado em si mesmo, identificando-se com quem sofre. "Falo de piedade, disposição conveniente a seres tão fracos e sujeitos a tantos males como o somos; virtude tanto mais universal e tanto mais útil ao homem quando nele precede o uso de qualquer reflexão, e tão natural que as próprias bestas às vezes são dela alguns sinais perceptíveis." (ROUSSEAU, Segundo Discurso, p. 259). Rousseau resume esse sentimento de piedade em três máximas fundamentalmente: Primeira Máxima: "Não pertence ao coração humano colocar-se no lugar de pessoas mais felizes do que nós, mas apenas no lugar das que estão em situação mais lastimável" (ROUSSEAU, Emílio, p. 290). Segunda Máxima: "Só lamentamos no outro os males de que não nos acreditamos isentos" (ROUSSEAU, Emílio, p. 291). Terceira Máxima: "A piedade que se tem pelo mal de outrem não se mede pela quantidade desse mal, mas pelo sentimento que atribuímos aos que sofre" (ROUSSEAU, Emílio, p. 292). Além disso, a 
educação para o amor de si acaba conduzindo o Emílio, em última análise, para ser um ser de paz e da paz.

\begin{abstract}
Esse espírito de paz é um efeito de sua educação, que, não tendo fomentado seu amor-próprio e uma alta opinião sobre si mesmo, evitou que ele buscasse seus prazeres na dominação e na infelicidade de outrem. Ele sofre quando vê sofrer; é um sentimento natural. Um jovem torna-se duro e encontra satisfação em ver o tormento de um ser sensível quando as vicissitudes de vaidade o fazem encarar-se como isento dos mesmos sofrimentos por sua sabedoria ou por sua superioridade. Aquele que foi protegido contra esse modo de pensar é incapaz de cair no vício que dele resulta. O Emílio ama, portanto, a paz. (ROUSSEAU, Emílio, p. 333).
\end{abstract}

A paixão do amor-próprio constitui-se de outro modo completamente diferente do amor de si. Por sinal, trata-se, por assim dizer, de uma espécie de antagonismo, utilizandose, aqui, de uma expressão kantiana, ou seja, trocando em miúdos, paradoxalmente, por um lado, tem-se o amor-próprio como fonte do orgulho, do egoísmo e da soberba. Nas próprias palavras de Rousseau, em uma nota de rodapé, do Segundo Discurso, amor-próprio: “[...] não passa de um sentimento relativo, fictício e nascido na sociedade que leva cada indivíduo a fazer mais caso de si mesmo do que de qualquer outro, que inspira aos homens todos os males que mutuamente se causam e que constitui a verdadeira fonte da honra." (ROUSSEAU, Segundo Discurso, p. 312). Porém, por outro lado, tem-se na paixão do amor-próprio como condição imprescindível ao ingresso no estado social. Ou seja, se é plausível a afirmação de que o sentimento do amor de si é condição para a compreensão do ser humano em seu estado natural como anterior ao estado social e moral, é, também, perfeitamente, razoável afirmar que o amor-próprio caracteriza a potencialidade social, racional e moral do ser humano (DALBOSCO, 2016, p. 96). De acordo com Strauss, é preciso buscar o fundamento da sociedade exclusivamente dentro do desejo de conservação ou também no chamado direito à conservação (STRAUSS, 1986, p. 244). Assim, segundo Rousseau, o amor-próprio, ainda que possa constituir-se, de início, na paixão avassaladora do egoísmo e da soberba, centrada no egoísmo de cada indivíduo isoladamente, em um segundo momento, torna-se, paradoxalmente, como força propulsora, isto é, como fonte primeira para a mudança notável da passagem do estado de natureza para a sociabilidade humana por meio do pacto fundamental. Nesse sentido, a liberdade e a igualdade em sociedade somente são possíveis graças ao reconhecimento total de cada um em favor da sociedade. O indivíduo perde o direito de invocar o direito natural contra os veredictos da sociedade, isto é, de invocar o direito natural contra a lei positiva (STRAUSS, 1986, p. 247). 
Por fim, convém salientar ser a formação e a educação para a virtude da convivência humana em sociedade uma tarefa imprescindível no pensamento políticopedagógico de Rousseau, tanto em nível pessoal quanto comunitário. O indivíduo precisa passar pelos diferentes momentos, etapas, espaços de pertença e instâncias, a fim de alcançar, a partir da faculdade constante e incessante da perfectibilidade, a virtude moral e social de uma sociedade de convivência, formada, eminentemente, por participantes solidários, dados à busca constante de uma sociedade cada vez mais justa.

\section{REFERÊNCIAS:}

BOTO, Carlota. O Emílio como categoria operatória do pensamento rousseauniano. In: MARQUES, José Oscar de Almeida (Org.). Verdades e mentiras. 30 ensaios em torno de Jean-Jacques Rousseau. Ijuí: Unijuí, 2005, pp. 369-387.

DA SILVA, Genildo Ferreira. Moral e virtude em Rousseau. In: PERES, Daniel Tourinho (Org.). Justiça, virtude e democracia. Salvador: Quarteto, 2006, pp. 101-123.

DALBOSCO, Claudio Almir. Condição humana e educação do amor-próprio em JeanJacques Rousseau. São Paulo: Loyola, 2016;

DOZOL, Marlene de Souza. Da figura do mestre. São Paulo: Edusp; Campinas: Autores Associados, 2003.

FERRY, Luc. Aprender a viver. Filosofia para os novos tempos. Rio de Janeiro: Objetiva, 2007.

MARQUES, José Oscar de Almeida (Org.). Verdades e mentiras. 30 ensaios em torno de Jean-Jacques Rousseau. Ijuí: Unijuí, 2005.

NETO, Manoel Dionizio, Liberdade e educação em Rousseau: da infância à adolescência. In: MARQUES, José Oscar de Almeida (Org.). Verdades e mentiras. 30 ensaios em torno de Jean-Jacques Rousseau. Ijuí: Unijuí, 2005, pp. 407-412.

PERES, Daniel Tourinho (Org.). Justiça, virtude e democracia. Salvador: Quarteto, 2006.

PISSARA, Maria Constança Peres. Rousseau. A política como exercício pedagógico. $2^{\mathrm{a}}$ ed., São Paulo: Moderna, 2005.

ROUSSEAU, Jean-Jacques. Discurso sobre a origem e os fundamentos da desigualdade entre os homens. In: ROUSSEAU, Jean-Jacques. Os Pensadores. São Paulo: Abril Cultural, 1973. (Segundo Discurso).

ROUSSEAU, Jean-Jacques. Discurso sobre as ciências e as artes. In: ROUSSEAU, JeanJacques. Os Pensadores. São Paulo: Abril Cultural, 1973. (Primeiro Discurso).

ROUSSEAU, Jean-Jacques. Do Contrato social. In: ROUSSEAU, Jean-Jacques. Os Pensadores. São Paulo: Abril Cultural, 1973. (Contrato Social).

\begin{tabular}{|c|c|c|c|}
\hline Q Ponista Dialectus & \begin{tabular}{l|l} 
Ano 8 & n. 15
\end{tabular} & Agosto - Dezembro 2019 & p. $253-267$ \\
\hline
\end{tabular}


ROUSSEAU, Jean-Jacques. Emílio ou Da educação. São Paulo: Martins Fontes, 1999. (Emílio).

STAROBINSKI, J. A transparência e o obstáculo. São Paulo: Companhia das Letras, 1991. STRAUSS, Leo. Droit naturel et histoire. Paris: Flammarion, 1986.

STRECK, Danilo. Rousseau \& a educação. Belo Horizonte: Autêntica, 2004. 